\title{
LOS CUERPOS EN LA CULTURA, LA CULTURA EN LOS CUERPOS. SOBRE LAS (NUEVAS) FORMAS DE HABITAR LA ESCUELA
}

\author{
Julieta Armella* \\ Sofía Dafunchio*
}

\begin{abstract}
RESUMEN: El presente artículo procura describir las formas que asume la vida escolar en contextos de pobreza urbana atendiendo, específicamente, a los modos corporales de estar en la escuela, indagando las formas en que los estudiantes habitan el espacio y el tiempo escolar a partir de la perspectiva del Embodiment: la experiencia corporizada como punto de partida para analizar la participación humana en el mundo cultural. (CSORDAS, 2011) Este trabajo se enmarca en un proyecto de investigación que se interroga sobre las características que presentan los dispositivos pedagógicos en emplazamientos urbanos de extrema pobreza de la Provincia de Buenos Aires, Argentina. Presentaremos avances de la investigación recuperando escenas observadas en el trabajo de campo en escuelas secundarias.
\end{abstract}

Palabras clave: Escuela. Embodiment. Espacio. Tiempo. Buenos Aires.

\section{THE BODIES IN THE CULTURE, THE CULTURE IN THE BODIES. ABOUT THE (NEW) WAYS OF INHABITING SCHOOL}

ABSTRACT: This article attempts to describe the forms school life assumes in contexts of urban poverty, attending specifically to bodily ways of being in school, investigating the ways through which students inhabit space and school time from the perspective of Embodiment: the embodied experience as a starting point for analyzing human participation in the cultural world. (CSORDAS, 2011) This work is part of a research project that questions the features of pedagogic tools present in extreme poverty urban settings in the Province of Buenos Aires, Argentina. We will present research advances by retrieving scenes observed in the fieldwork in secondary schools.

Keywords: School. Embodiment. Space. Time. Urban poverty. Buenos Aires.

\footnotetext{
* Universidad de Buenos Aires, Buenos Aires, Argentina. E-mail de contato: juli.armella@gmail. com.
} 


\section{LES CORPS DANS LA CULTURE, LA CULTURE DANS LES CORPS. SUR LES (NOUVELLES) FAÇONS D'OCCUPER L'ÉCOLE}

RÉSUMÉ: Le but de cet article est de décrire les formes qui prennent la vie scolaire dans des contextes de pauvreté urbaine, en observant plus spécifiquement la manière que les apprenants prennent possession de l'espace et du temps scolaire à partir de la perspective de l'Embodiment c'est-à-dire, l'expérience corporelle comme point de départ pour l'analyse de la participation humaine dans le monde culturel. (CSORDAS, 2011) Ce travail fait partie d'un projet de recherche autour des caractéristiques des dispositifs pédagogiques mis en place dans les sites urbains d'extrême pauvreté de la Province de Buenos Aires, en Argentine. Nous présenterons les avancées des travaux de recherche en exposant des scènes observées sur le terrain, dans des écoles secondaires.

Mots-clés: Ecole. Embodiment. Espace. Temps. Buenos Aires. Pauvreté Urbaine.

\section{Introducción}

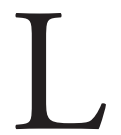

as aulas escolares, durante casi dos siglos, han presentado una configuración similar, es decir, han sufrido pocas modificaciones que alteraran su forma "original": espacios cerrados, disposición misal de alumnos y maestros, criterio de distribución basado en franjas etarias, instrucción simultánea, monopolio de la transmisión unidireccional del saber escolar (del maestro hacia el alumno), método de enseñanza único, evaluación individual de los alumnos, cuerpos fijos e inmóviles y un silencio que se garantizaba, fundamentalmente, a partir de los principios de autoridad, obediencia y disciplina. (VARELA; ÁLVAREZ URÍA, 1991; PINEAU, 2001; FRIGERIO; DICKER, 2005) En esta configuración espacio-temporal cada sujeto ocupaba un lugar determinado en el espacio del aula: cuerpos fijos, silenciosos, obedientes. Un cuerpo escolarizado debía ser capaz de estar sentado por muchas horas y tener la habilidad de expresar gestos y comportamientos indicativos de interés y de atención, aunque fueran falsos. Un cuerpo disciplinado por la escuela debía ser entrenado en el silencio y en un determinado modelo de habla, concebir y utilizar el tiempo y el espacio de una forma particular. Manos, ojos y oídos estaban adiestrados para tareas intelectuales, mas posiblemente desatentos o torpes para otras tantas. (LOPES LOURO, 1999)

De este modo, desde la conformación de los sistemas educativos, la organización del espacio y del tiempo escolar significó el disciplinamiento de los cuerpos - cada sujeto en un lugar y un tiempo determinado. Disciplinamiento "que parte del principio que es más rentable vigilar que castigar, normalizar y 
hacer productivos a los sujetos que segregarlos" (VARELA; URÍA, 1991) y que se valió de tecnologías de individualización y de regulación de la población. La búsqueda de una sociedad disciplinada y productiva se entrelazaba con los radicales cambios operados en el nuevo sistema, y el nuevo tipo de relaciones sociales que se establecieron: el capitalismo y las transformaciones aparejadas en los distintos ámbitos, como el político - construcción del Estado Moderno -, el orden social - demanda de seguridad como necesidad de sectores dominantes -, el orden económico - desarrollo de la industrialización - y el cultural - defensa y aceptación de un nuevo orden social.

Distintas investigaciones dieron cuenta de las formas que asumió la escolaridad en el mundo moderno estableciendo que ese orden significaba el encauzamiento de conductas de un conjunto de la población, sobre la base de una desigualdad existente, lo que en otras palabras significó la dominación de una clase social por sobre otra. (VARELA-ÁLVAREZ URÍA; 1991) A la modernidad le correspondió un tipo de dispositivo pedagógico donde se configuraban, a través de la regulación del tiempo y del espacio, formas de entender el mundo (ROLDAN, 2009). Muchos de los elementos centrales que componían esta formación histórica moderna son puestos hoy en tensión por las propias subjetividades que habitan las escuelas. Estas tensiones son las que nos interesa describir. La pregunta que guía este escrito gira en torno de las maneras corporales de habitar cotidianamente la escuela.

Derivado de la voz latina habitare, "habitar" remite a ocupar un lugar con cierta regularidad, a "vivir en él”. Se define genéricamente como la acción humana que, desplegada en el espacio que rodea al cuerpo, lo organiza, lo ocupa, lo coloniza. Así, puntualiza Lewkowicz (2003), el hecho mismo de habitar trae consigo la producción de un espacio y de un tiempo, es su determinación temporal-espacial. Habitar no es un mero estar, señala, sino un construir constante: no de una vez y para siempre, sino una tarea permanente de colonización del espacio conquistado. Un habitante, en ese marco, no será sino la subjetividad capaz de forjar y transitar una situación. $\mathrm{O}$, mejor, es el que hace, de una situación cualquiera de la que forma parte un mundo, su mundo.

Nuestro interés aquí está centrado en el análisis de los modos corporales en que los estudiantes habitan el espacio y el tiempo escolar asumiendo como supuesto básico que el dispositivo pedagógico moderno se encuentra en un proceso de reconfiguración (GRINBERG, 2008) en el marco de las actuales sociedades de control (DELEUZE, 1991) en las que se profundiza la aceleración del tiempo, la modificación de los espacios y la circulación fluctuante y virtual de los cuerpos.

Cabe señalar que un dispositivo supone la organización de algo, la composición de distintas partes o elementos que, ensamblados, producen determinados resultados o efectos. Así, Foucault (1984, p. 184) entiende que un dispositivo es: 
[...] un conjunto heterogéneo, que implica discursos, instituciones, disposiciones arquitectónicas, decisiones reglamentarias, leyes, medidas administrativas, enunciados científicos; proposiciones filosóficas, morales, filantrópicas; en síntesis, tanto lo dicho cuanto lo no dicho, he aquí los elementos del dispositivo $[\ldots]$ es la red que puede establecerse entre esos elementos [...], entre dichos elementos - discursivos y no discursivos - existe algo así como un juego, cambios de posición, modificaciones de funciones, que pueden, también ellos ser muy diferentes.

En ese marco, la noción de dispositivo pedagógico refiere a una amplia gama de aspectos a considerar, tales como la organización y el uso del espacio, la disposición del mobiliario, la racionalidad en el uso del tiempo para alumnos y docentes, la organización del horario escolar, la distribución de los cuerpos en el espacio, la organización y secuenciación de las tareas escolares, la vestimenta apropiada para la escuela, el uso de la palabra y las formas de comunicación, los textos escolares, la circulación de los saberes y contenidos curriculares, el reglamento escolar y las medidas de sanción, el control de asistencia, el sistema de calificaciones, las rutinas y rituales escolares. Esto es, una batería de detalles que conforman técnicas y procedimientos vinculados con la producción de subjetividad. (DEAN M., 1999; ROSE N.,1999; GRINBERG S., 2008)

Asimismo, los dispositivos son siempre formaciones históricas. De manera que los modos que asumen estos dispositivos pedagógicos que estamos estudiando sólo pueden comprenderse en el seno de unas determinadas relaciones sociales, en las que el control predomina por sobre el disciplinamiento (FOUCAULT, 2002; DELEUZE, 1991; GRINBERG, 2007; 2008). En ellas, el Estado y los sujetos asumen una nueva dirección. Dice Deleuze (1991, p. 3):

\footnotetext{
El viejo topo monetario es el animal de los lugares de encierro, pero la serpiente es el de las sociedades de control. Hemos pasado de un animal a otro, del topo a la serpiente, en el régimen en el que vivimos, pero también en nuestra forma de vivir y en nuestras relaciones con los demás. El hombre de las disciplinas era un productor discontinuo de energía, pero el hombre del control es más bien ondulatorio, en órbita sobre un haz continuo. Por todas partes, el surf ha reemplazado a los viejos deportes.
}

Nos preguntamos entonces ¿cuáles son las formas corporales de habitar el tiempo y el espacio escolar en las actuales sociedades? Específicamente nos abocaremos a describir esos modos corporales en escuelas secundarias emplazadas en contextos de profunda desigualdad social desde una perspectiva sociopedagógogica, al mismo tiempo recuperaremos la perspectiva del Embodiment para abordar el 
estudio de los cuerpos en tanto "sustrato existencial de la cultura". (CSORDAS, 2011)

Los relatos aquí incluidos forman parte de los avances del trabajo de campo que estamos realizando en escuelas secundarias de José León Suárez- Partido de San Martín, Provincia de Buenos Aires, Argentina. En este escrito presentamos dos escenas recogidas en una escuela secundaria de la zona en la que venimos trabajando desde 2008. En ella hemos realizando entrevistas formales e informales con estudiantes y docentes de diferentes cursos, observaciones no participantes de distintas clases, a la vez que contamos con material fílmico -ya que realizamos una vez por semana talleres documentales con estudiantes de la institución. Asimismo, durante 2011 hemos realizado encuestas en 15 escuelas secundarias públicas del Partido de San Martín.

La escuela que tomamos como caso es una secundaria pública urbana, emplazada dentro de uno de los distritos del Área Metropolitana de Buenos Aires que registra los más altos índices de pobreza y desigualdad social y, si bien su edificio no está ubicado en medio de ninguna de las villas miseria ${ }^{1}$ de la zona, por tratarse de la única escuela estatal - diurna - que ofrece el nivel secundario completo, concurren a ella muchos de los jóvenes provenientes de los barrios denominados "villas". Es a causa de esa confluencia de alumnos provenientes de distintos fragmentos espaciales del Distrito - con sus rasgos en común, pero, también, cada uno con sus particulares identidades - que esa escuela se nos presenta como un caso interesante para la investigación y la intervención.

\section{Algunas precisiones conceptuales}

¿Qué implica recuperar una perspectiva teórica que se interrogue por las formas que asumen los cuerpos en el espacio escolar? Y hacerlo atendiendo a dos coordenadas específicas como son el espacio y el tiempo en la escuela. En principio, podemos decir que lo que nos interesa no es tanto el cuerpo como objeto de estudio en sí mismo sino como forma de pensar y analizar la cultura en nuestro presente. Esto es, el cuerpo en tanto que "sustrato existencial de la cultura". (CSORDAS, 2011, p. 83) La experiencia corporizada como punto de partida para analizar la participación de los sujetos en el mundo cultural.

Una primera distinción hace referencia a los modos que ha asumido, fundamentalmente en la antropología, el estudio del cuerpo: aquella que toma al cuerpo como objeto de estudio en sí mismo, denominada Antropología del cuerpo y aquella parte de la fenomenología que se interesa por el Embodiment.

Tal como señalan Del Mármol y otros (2008), a pesar de que puedan identificarse algunos trabajos pioneros de principios del siglo XX (HERTZ, 1907; 
MAUSS, 1934), los campos de la antropología y la sociología del cuerpo recién se iniciaron entre 1970 y 1980 . Hasta entonces, el cuerpo no había sido problematizado de manera sistemática desde las ciencias sociales, quedando su estudio relegado, principalmente, al campo de las ciencias biológicas. Diversos autores encuentran que tal proceso de invisibilización del cuerpo está principalmente vinculado con el dominio del enfoque dualista propio del pensamiento occidental. En este sentido, tal como afirma Citro, la tradición platónica y judeocristiana, incluso el pensamiento griego previo, conciben la oposición entre un alma inmortal y divina vinculada al intelecto y un cuerpo sensible que es su cárcel y tumba. Esta larga tradición de debates acerca de la relación mente-cuerpo, encontrará en Descartes durante el siglo XVII la "desanimación y desantropomorfización del mundo que sentaría las bases filosóficas de la ciencia moderna” (CITRO, 2010, p. 23) distinguiendo la res cogitans - cosa pensante - de la res extensa - como sistema material y mecánico regulado por las leyes de la matemática y despojado de toda intención y materialidad.

A pesar de esta fuerte impronta del pensamiento dualista, a lo largo de todos estos siglos, han existido líneas teóricas que han resistido a tal concepción. Al idealismo de Platón se le oponía la escuela cirenaica de Aristipo, que veía a la sensación como el criterio de verdad y de la conducta práctica, postulando el placer como fin del ser humano. Asimismo, la escuela cínica de Antístenes, que planteaba el bien del ser humano en la reivindicación de la naturaleza.

Baruch Spinoza, en el siglo XVII, se declarará monista, planteando la no existencia de un dualismo cuerpo-alma. Para este filósofo, el hombre es cuerpo y mente, y ese conjunto es parte de una sustancia universal con infinitos modos e infinitos atributos. "El alma y el cuerpo, nadie tuvo jamás una idea tan original de la conjunción «y»". (DELEUZE, 1980, p. 69) Más acá en el tiempo, será el semiólogo ruso Mijaíl Bajtín quien a partir de su estudio sobre las culturas populares de la Edad Media y el Renacimiento señale la reivindicación que éstas hicieron al cuerpo bajo y material y a los placeres que eran condenados por la Iglesia.

Desde la voluntad de poder de Nietzsche o desde el concepto de pulsión de Freud, ambos pensadores darán continuidad a esta dirección alternativa en relación con la concepción del cuerpo, reconociendo en él un lugar positivo y productivo.

Retomando la pregunta por los motivos de la invisibilización del cuerpo en el pensamiento hegemónico moderno, Citro sostiene que serán las mismas prácticas sociales las que se harán eco del cuerpo-máquina planteado por Descartes. A partir del concepto de enajenación Marx evidencia los modos a través de los cuales el cuerpo del hombre deviene máquina-herramienta separada del ser.

Foucault por su parte, también será un autor clave para comprender las formas en que el cuerpo es convertido en una máquina útil y disciplinada 
que transitará por las distintas instituciones de encierro de la naciente sociedad moderna y será blanco de dos formas que asume el poder a partir del siglo XVII: el poder disciplinario y el poder bio-político, estableciendo así una distinción entre aquel poder que actúa sobre el cuerpo/individuo y aquel que lo hace sobre la población en tanto que especie humana.

Como cierre de una genealogía que evidencia la tensión entre aquella perspectiva dualista hegemónica y el conjunto diverso de autores que problematizan esa mirada, Citro menciona los aportes de Norbert Elias, sociólogo polaco, cuya obra, previa a la de Foucault, tiene algunos puntos en común con éste: la formación de la "civilización occidental" que para el autor abarca el período comprendido entre los siglos XIII y XIX. En su hipótesis sostiene que las transformaciones en las estructuras de la personalidad son consecuencia del devenir de las estructuras sociales. Así, plantea, los cambios en los comportamientos de la vida cotidiana se evidencian "[...] en los cambios en las actitudes frente a las necesidades fisiológicas del cuerpo, las maneras de mesa, las relaciones entre hombres y mujeres, y las transformaciones de la agresividad [...]”. (CITRO, 2010, p. 30) El autodominio del sujeto con especial énfasis en el cuerpo y los afectos será un rasgo muy valorado de la personalidad.

No será sino hasta la década del 1970, decíamos al comienzo, que una parte del campo de la antropología se conformará como núcleo interesado en el estudio sobre el cuerpo. Época signada por las más disímiles expresiones de nuevas corporalidades y valoraciones hacia los cuerpos: los movimientos contraculturales - como el movimiento hippie - comienzan a evidenciar (hacer visible) al cuerpo como fuente de placer y conocimiento sensible. A los intentos de regulación de la vida se opondrán los del amor libre, la experimentación con drogas o técnicas corporales que procuran ampliar los límites perceptivos a la vez que se oponen a la racionalidad como valor supremo.

En este marco, comienzan a surgir algunos autores que tendrán un marcado interés por analizar los cambios de aquel momento.

Es el caso de Mary Douglas, quien comprenderá al cuerpo no sólo en su dimensión "objeto y medio técnico" que hay que describir sino analizarlo a partir de su dimensión simbólica, como "microcosmos de la sociedad"

La década del 1980 marcará el inicio de un conjunto de transformaciones en las prácticas y representaciones sobre los cuerpos, vinculadas a los procesos de globalización que han generado nuevas formas de subjetivación. Aquí los trabajos de Bourdieu tendrán especial relevancia, sobre todo a partir de la noción de Habitus y sus estudios sobre el cuerpo.

Finalmente, en esta misma línea podemos identificar los aportes de Csordas de la década del 1990 a partir del desarrollo de la perspectiva del Embo- 
diment, que ubica al cuerpo vivido en una aproximación fenomenológica, como punto de partida metodológico antes que como objeto de estudio.

Así, desde las ciencias sociales se pueden distinguir básicamente tres líneas de abordaje:

- Aquella que destaca el carácter político del cuerpo. El cuerpo es entendido como lugar de inscripción de los discursos sociales, atravesado por dispositivos de disciplinamiento, normalización, vigilancia y control. Aquí se pueden encontrar los trabajos de Foucault, Agamben, Lock, Butler.

- Una segunda línea, propone abordar al cuerpo como representación, como fuente de simbolismos o medio de expresión. El cuerpo es visto como producto de un conjunto de sistemas simbólicos socialmente compartidos y atravesado por significaciones que constituyen la base de su existencia individual y colectiva. Aquí se enmarcan los trabajos de Mary Douglas, Geertz, Heritier, Le Bretón.

- Por último, podemos identificar una tercera perspectiva que parte de la crítica a los enfoques netamente representacionales que perciben al cuerpo sólo como signo o símbolo, lo que ha hecho que sea considerado como pasivo e inerte. Este enfoque destaca el carácter activo y transformador de la praxis corporal en la práctica social y se propone recuperar la perspectiva del embodiment.

Cuerpos, entonces, que a lo largo de la historia fueron disciplinados, silenciados, convertidos en engranaje funcional de la compleja máquina del capitalismo. Cuerpos que, sin embargo, nunca han sido del todo reprimidos. Cuerpos que se rebelan, se propagan, se materializan de una y mil maneras. Repasemos, entonces, algunas escenas escolares y analicemos a partir de ellas los modos en que los cuerpos se hacen presentes bajo algunas coordenadas puntuales.

\section{Escenas escolares}

Jueves de invierno por la mañana. Clase de físico-quimica. $3^{\circ}$ año.

Hay 18 estudiantes presentes. Volvemos del recreo. Los chicos van entrados, de a poco. Mientras espera que se acomoden, el Docente (D) escribe en el pizarrón "Una caloría es la cantidad de energía que necesita 1 gramo de agua para calentarse $1^{\circ} \mathrm{C}$ ”.

Varios estudiantes entran después de hora, con sus celulares sonando muy fuerte al ritmo del reggaetón. 
D - "Se sientan de una vez, chicos. Siéntate, por favor" le pide a $16^{2} .14$ tiene el celular de 16.

D comienza a explicar. 16 mira para atrás, 14 para el costado. 11, 12 y 13 conversan, hacen comentarios sobre la música que escuchan.

$6,7,8,9$ y 19 miran hacia el frente con la cabeza recostada sobre el escritorio, como evidenciando aburrimiento.

11 le pide a $\mathrm{D}$ permiso para ir a comprar un sándwich. Sale.

19 está parada al lado de 6. D le pide que vuelva a su lugar. D intenta continuar con la clase.

14 y 16 se paran. Comienzan a contar y repartir unas tarjetas que dicen "Infierno Facebook". Parecen ser de un boliche.

D comienza a escribir preguntas en el pizarrón.

1 escribe prolijamente en una hoja “¿Qué es un metabolismo celular?” y comienza a resumir un texto de biología.

3 pregunta a D -"Profe, no entiendo ¿̨qué es una caloría?"

(Registro de observación de clase de físico-química. $3^{\circ} 1^{\circ}$. T.M. 14 de julio de 2011.)

Jueves de invierno por la mañana. Clase de físico-química. $3^{\circ}$ año.

Comienza la clase con la propuesta de D de utilizar las netbooks del Programa Conectar Igualdad que entregaron días antes de las vacaciones de invierno. D les pide que abran el Programa Abogadro para realizar una animación de moléculas.

D- "Se pueden crear movimientos. Hay una opción en Preferencias de herramientas. Hagan clic ahí". Suena reggaetón de fondo. D- "Fíjense que ahí les muestra un elemento. Son los elementos que se pueden graficar”. Suena música muy fuerte. D pide que la apaguen. Algunos pocos - estudiantes comienzan a trabajar con el Programa.

20- "Ni la tele se puede mirar!", se ríe.

19- "Es que la chica está viendo Panam!" grita.

$\mathrm{D}$ vuelve a pedir que bajen la música.

8 y 9 están chateando con alguien, conversan entre ellos sobre lo que les dice Sami, su amiga virtual. Se escuchan diálogos de un video de youtube. D les pide que apaguen el video. Continúan. $\mathrm{D}$ se acerca a 8 y 9 y les pide que se pongan a trabajar. Les explica algo del Programa.

14- "Chupame el cabezón" grita al compás de la música. D le pide que se retire del aula. 14- “¿Por qué profe?” D- "Porque sî”. 14 se queda. D se acerca y lo ayuda para que empiece a trabajar.

20 se para y se acerca a la puerta, quiere salir. D no lo deja.

19 también quiere salir, abre la puerta y se va igual. Entra de golpe. 20 sale sin avisar. Vuelve con galletitas. 
D está rodeado de algunos estudiantes, les explica cómo componer la molécula. Hay mucho ruido, gritos. D se acerca a 9, le explica algo.

La clase transcurre entre música, gritos, YouTube y estudiantes que alternativamente hacen la actividad y salen y entran del aula.

19 sale del aula. Suena el timbre del recreo. Ninguno se para. Hay silencio por primera vez.

8 le pregunta algo a D sobre la tarea. Casi todos están sentados en sus bancos. No salen al recreo.

D sigue ahí, explicándole algo a 18. 8, 9 y 20 miran la pantalla y se ríen. No alcanzo a ver que miran.

(Registro de observación de clase de Físico-química. $3^{\circ} 1^{\circ}$. T.M. 10 de agosto de 2011.)

Dos escenas. Dos situaciones registradas en una escuela secundaria pública del Partido de San Martín. Un recorte, se podría objetar. Como todo - y la investigación social por cierto no está exenta de ello - una selección supone indefectiblemente una mirada arbitraria sobre una situación. Sin embargo, son situaciones que se repiten una y otra vez en las aulas. En ésta y en muchas otras.

¿Qué nos sugieren, entonces, estas escenas? ¿Qué nos dicen esos cuerpos que hablan en su andar?

"Los hombres se parecen más a su tiempo que a su padre", sostiene Debord (1988) en una de sus tesis sobre la sociedad del espectáculo. Tenemos aquí una primera pista. Los cuerpos se presentan más como insumo para analizar la cultura del presente que para rastrear líneas de continuidad respecto de otros tiempos, de otras generaciones.

Cuerpos que habitan un tiempo y un espacio determinados: un presente. Presente compuesto por una compleja red de elementos que, además, entrecruza un pasado y un futuro.

Analicemos estas escenas a través de los cuerpos que habitan esos espacios y esos tiempos.

\section{Permanencias nómadas. Tiempos atemporales}

$$
\begin{array}{r}
\text { Nómadas son los que no se mueven, se convierten en nómadas } \\
\text { porque se niegan a partir. } \\
\text { Arnold Toynbee }
\end{array}
$$

Si algo caracteriza, hoy, el modo de habitar el espacio escolar, es una constante e incesante circulación de personas dentro y fuera del aula. Permanencias 
nómadas: así podríamos denominar esa forma de habitar la escuela. En una de sus acepciones, el término nómada refiere a aquellos pueblos o comunidades que se trasladan de un lugar a otro, sin establecerse de forma permanente en un solo sitio. La permanencia, en cambio, designa el mantenimiento de determinados elementos a través del tiempo (sean estos personas, fenómenos u objetos). Ambas se presentan, en principio, como mutuamente excluyentes: se permanece en un cierto lugar o se marcha de él. Un contrasentido, o específicamente, un oxímoron, con el pasaje de una aparente figura retórica a un nuevo concepto, a ese hacer del filósofo que señalaba Deleuze.

Decíamos que este estar de los cuerpos, de estos cuerpos, su presencia en la escuela, es una permanencia nómada. Pibes que circulan por el aula. Por la escuela. No tienen lugar fijo: cada día pueden estar en un lugar distinto. Con un compañero diferente. $\mathrm{O}$ solos. Piden permiso para salir una y mil veces. $\mathrm{O}$ salen sin permiso. Van al baño, a la biblioteca, a buscar tizas, borradores, al kiosco. A caminar... ¿Qué importa? Y vuelven. Pibes - de otros cursos - que entran al aula (por la puerta, por la ventana...).

¿Son éstas formas de no-estar? ¿De ausentarse? ¿De huir? Es interesante la diferencia que Deleuze establece entre los emigrantes y los nómadas. Los nómadas, dice, son gente que no viaja. Los que viajan son los emigrantes, ese es un tipo de viaje que no hay que tomar a la ligera porque son viajes sagrados, forzados. Pero los nómadas viajan poco. Permanecen literalmente inmóviles, porque se aferran a su tierra que es indiferenciada de otros espacios. Nomadizan a fuerza de querer quedarse en ella. Son nómadas porque no quieren irse. (DELEUZE, 1980)

Quizás estas son formas - nuevas o ahora más visibles - de habitar ese territorio. Se permanece sólo a condición de estar en movimiento. Dardo Scavino (1991) plantea que los estoicos son los primeros que dejan de pensar al movimiento como tránsito al acto para sostener que es acto en sí mismo. ¿Y cómo es ese acto? ¿Cómo es ese movimiento? Por momentos, es un andar lento: estudiantes que entran y salen. Ingresan al aula sin apuro, sin evidenciar gestos de preocupación, conversando con algún compañero, escuchando música o mirando el celular, mientras el docente continúa la exposición de su clase. $\mathrm{O}$ estudiantes sentados, con sus mochilas puestas. Mochilas que, a veces, no se abren en toda la jornada. Mochilas que permanecen en las espaldas de quienes las transportan.

¿En qué medida, para estos nómadas, la escuela ya no es lo otro respecto de la casa o la calle, sino su continuidad? ¿En qué medida el aula se vuelve, no ya un espacio de corte con la vida cotidiana, sino un espacio más en el que desplegar un modo de vida no propiamente escolar, pero que tampoco le es ajeno?

Los nómadas se aferran al territorio porque es indiferenciado, no hay una producción de diferentes lógicas acordes a distintos territorios afín a los parámetros modernos. Las lógicas internas, disciplinarias, que hasta ayer constituían 
y regulaban el territorio escolar conviven hoy con aquellas incipientes marcas que señalan nuevos modos de actuar sobre y (de) los cuerpos. Podríamos pensar junto a Foucault que los mecanismos disciplinares propios de las instituciones de encierro modernas se entrecruzan con nuevas formas de "dejar hacer" a los cuerpos en el espacio y en el tiempo. ${ }^{3}$ (FOUCAULT, 2006) Si hasta hace algunas décadas a cada fracción de tiempo le correspondía una determinada tarea que todos los estudiantes realizaban a la vez ${ }^{4}$ hoy encontramos la coexistencia de múltiples - y diversas - operaciones en simultáneo. Así, el orden cronológico y progresivo da paso a la multifuncionalidad que supone la red.

Los estudiantes circulan por el espacio/tiempo del aula-red. Algunos salen y vuelven a entrar. Conversan con sus compañeros, miran hacia atrás, hacia el costado. Descansan sobre sus bancos. Miran sus celulares, se los prestan o intercambian. Escuchan música. Comparten en Facebook algo que pasó en la clase o en ella socializan algo que se publicó en el espacio virtual. El docente - entre el espacio y el tiempo de su clase - intenta continuar con su propuesta. La bidireccionalidad estalla y el centro pierde su centralidad: las direcciones son múltiples, los focos de atención diversos. Son pocos o esporádicos los momentos de atención dirigida colectivamente hacia un mismo punto.

A veces, allí todo sucede lentamente. A veces el tiempo se hace eterno. Y de pronto, de forma imprevista, se vuelve convulsivo, revulsivo, inquietante, caótico. Un tiempo que de golpe estalla y se acelera. Una voz, un grito, conversaciones en paralelo, música estridente. Tiempos en simultáneo: como si este dejara de ser común y se fraccionara en temporalidades heterogéneas, inconexas, múltiples. Manuel Castells (2002) utiliza el concepto de tiempo atemporal para denominar a ese fenómeno propio de la sociedad red en el que el tiempo se comprime y las cosas suceden en simultáneo, rompiéndose la linealidad de los eventos.

[...] el tiempo lineal, irreversible, medible y predecible se está haciendo pedazos en la sociedad red, en un movimiento de significado histórico extraordinario. Pero no sólo estamos siendo testigos de una relativización del tiempo según contextos sociales o, de forma alternativa, del regreso al carácter reversible del tiempo, como si la realidad pudiera captarse del todo en movimientos cíclicos. La transformación es más profunda: es la mezcla de tiempos para crear un universo eterno, no autoexpansivo, sino autosostenido, no cíclico sino aleatorio, no recurrente sino incurrente: el tiempo atemporal, utilizando la tecnología para escapar de los contextos de su existencia y apropiarse selectivamente de cualquier valor que cada contexto pueda ofrecer al presente eterno". (CASTELLS, 2002) 
Algo de esto parece estar presente en estas clases. El tiempo atemporal invade las aulas: impredecible, incierto y aleatorio tiempo escolar. Retomemos la segunda escena: "La clase transcurre entre música, gritos, YouTube y estudiantes que alternativamente hacen la actividad y salen y entran del aula: un estudiante sale del aula. Suena el timbre del recreo. Ninguno se para. Hay silencio por primera vez. Uno le pregunta algo al docente sobre la tarea. Casi todos están sentados en sus bancos. No salen al recreo". Un tiempo que varía según la situación, el tiempo cronometrado de clase y ocio da lugar al tiempo ondulatorio según la contingencia y las diversas circunstancias. Si durante el siglo XIX y buena parte del siglo XX la escuela fue un espacio privilegiado en el que el par atención/distracción estuvo regulado y contenido - mediante la disciplina - a partir de la distinción precisa entre el "momento de trabajo" (la clase) y el "momento de descanso" (el recreo $)^{5}$, estas clases parecieran organizarse a partir de la alteración del vínculo entre estos términos: clase/recreo o trabajo/descanso o atención/distracción, lejos de oponerse, se implican de un modo particular: una indiferenciación que tensa la tradicional forma de organización del espacio y el tiempo escolar. Contradiciendo los clásicos lineamientos cartesianos - cuantificación y extensión - el tiempo pasa de ser medido de manera cuantificable, fragmentada e idéntica a ser una categoría que depende primeramente de la cualificación. De esta manera, observamos una disrupción de la medida del tiempo.

Deleuze (1991) refiere a este fluctuante movimiento temporal en las actuales sociedades de control en las que el auto-control y la gestión de sí predomina sobre el disciplinamiento. Los sujetos están llamados, aquí, a actuar sobre sus propios cuerpos y autocontrolar el tiempo y el espacio según la situación lo delimite.

Permanencias nómadas, tiempos atemporales, decíamos al comienzo, como modos de habitar y estar presentes en la escuela, en las aulas, más allá de las circunstancias.

\section{Conclusión}

Y, en todas partes, mezclas que hay que desenredar: producciones de subjetividad que escapan a los poderes y saberes de un dispositivo para reinstalarse en los de otro, bajo otras formas que aún no han emergido.

Gilles Deleuze

En ¿Qué es un dispositivo? Deleuze (1990, p. 3) propone: 
Lo actual no es lo que somos sino más bien, aquello en que nos convertimos, aquello en que nos estamos convirtiendo, es decir, el Otro, nuestro devenir-otro. En todo dispositivo hay que distinguir lo que somos (que es lo que ya no somos) y aquello en lo que nos estamos convirtiendo: la parte de la historia y la parte de lo actual.

En este trabajo hemos intentado por aproximación, por ensayo, por error, por el mero hecho de ser arrojados a este acontecimiento y actuar en/con él, hacer cuerpo estas palabras. En definitiva, poder pensar cuáles son las condiciones de nuestro presente para encontrar en él aquello en que nos estamos convirtiendo.

$\mathrm{Si}$, como señala Foucault, en todo dispositivo hay líneas de sedimentación, líneas de fractura, de fisura, desenredar, hacer aún más explícitas esas líneas, es uno de los ejes principales que nos hemos propuesto al abordar este trabajo. Los cuerpos son, acaso, una buena excusa, un posible modo para cartografiar nuestro presente, y ver aquello en que nos estamos convirtiendo, hacia donde vamos, porque si bien nos es imposible conocer nuestro futuro, sí nos es dado trazar y/o conocer las líneas hacia donde tiende.

Si la escuela ha sido uno de los elementos fundantes de la modernidad, lo ha sido a condición de producir cuerpos acordes a las necesidades de un determinado régimen político y económico: ha producido cuerpos dóciles capaces de ser buenos trabajadores, buenos ciudadanos. Cuerpos que, disciplinados, se han invisibilizado, han devenido parte constituyente de la consagración de la escena moderna.

Pensar hoy los cuerpos en movimiento supone analizarlos en función de la emergencia de otras condiciones, que son nuevas, cambiantes y flexibles - por lo menos en el marco del capitalismo actual. Al hacerlo, la escuela habilita una reflexión en torno a las transformaciones de un dispositivo en el que conviven huellas y marcas del pasado, del presente y del futuro, que deviene.

Permanencias nómadas, una vez más, como modo de nombrar ese habitar de los cuerpos. Un estar ahí, un permanecer en un lugar en movimiento, rompiendo y quebrando las sedimentadas marcas disciplinarias, obligando a una fluidez de registros y afirmando la existencia de ese otro que fluye, que deviene.

Tiempos atemporales, una de las formas de enunciar temporalidades múltiples que conviven en simultáneo, cohabitan, y se entremezclan, con las permanencias nómades que mencionamos, y donde la inmediatez como destino marca y encarrila, sinuosamente, la multiplicidad de acontecimientos en la que estamos inmersos.

En este juego de tensiones, de permanencias que se mueven, de tiempos simultáneos con lógicas propias, la escuela hace equilibrio como una institución 
que se ve atrapada, constituida, por el resquebrajamiento del relato moderno, al que se aferra mientras los cambios sistémicos y los sujetos le imponen un funcionamiento con otra lógica.

No hay cuerpos completamente quietos. No hay cuerpos totalmente silenciosos. Hay cuerpos que colonizan un tiempo y un espacio, que lo hacen propio, que construyen un mundo, se lo apropian, hacen su mundo.

\section{Notas}

1. En Argentina, se denomina 'villas de emergencia', 'villas miseria' o sencillamente 'villas' a espacios urbanos densamente poblados en los cuales la mayor parte de su población - si no toda - vive en condiciones de pobreza - mayoritariamente extrema -; fruto del empobrecimiento de amplios sectores sociales, comenzaron a construirse, por lo general de manera no planificada, en terrenos fiscales o desocupados, como conglomerados de viviendas provisorias, por familias que habían perdido sus viviendas, o no poseían ni encontraban otros espacios para vivir. El carácter provisorio de estas viviendas se percibía, por ejemplo, en la precariedad de los materiales con que estaban construidas (cartones, chapas, sobre piso de tierra) y en el trazado de los barrios (en muchos de ellos estaban ausentes las calles). Hoy en día, la provisorio dejó paso a la permanente - de las viviendas, pero, lo que es más importante, de su precariedad -: a las familias que viven allí desde hace muchos años, se agregan, cada día, y aún más con cada crisis socio-económica, más familias que, aunque posiblemente tengan planes de irse, saben que lo más probable es que tengan que quedarse.

2. A los efectos de preservar la identidad de los estudiantes y como modo de registrar individualmente el movimiento de los cuerpos en el espacio, hemos elegido utilizar el registro numérico de los estudiantes presentes en las escenas escolares.

3. Foucault en Seguridad, Territorio y Población establece este pasaje o transición de las "sociedades disciplinares" a las "sociedades de empresa" (o de control) y el consiguiente cambio de los dispositivos disciplinarios a los dispositivos de seguridad. Si bien no es objeto de este escrito el análisis de esta transición cabe aclarar siguiendo el estudio de García Fanlo que la "[...] transición implica una coexistencia entre lo que va dejando de ser actual (sociedad disciplinaria) y lo que va deviniendo en actual (sociedad de control) pero también implica que los dispositivos no son reemplazados por otros, sino que todos se integran dentro de la red de poder-saber de modo que los dispositivos disciplinarios siguen disciplinando pero, a la vez, son integrados a nuevas funciones de control [...]". (2011, p.7)

4. Tal como señala Foucault (1976) los procedimientos disciplinarios han hecho aparecer un tiempo lineal cuyos procedimientos se integran unos con otros, orientándolo hacia un punto terminal y estable. Así, en las escuelas elementales del siglo XIX el recorte del tiempo se hace cada vez más sutil, las actividades se realizan en función de órdenes precisas que hay que responder. Cada hora, cada minuto, se encuentra regulado. En la enseńanza mutua, a principios de siglo XIX, el empleo del tiempo está íntegramente normalizado: "8h45 entrada del instructor, 8h52 llamada del instructor, 8 h56 entrada de los niños y oración, 9h entrada en los bancos, 9h04 primera pizarra, etcétera” (154). De esta manera, el tiempo deviene mecanismo de disciplinamiento del cuerpo. El cuerpo sólo se convertirá en fuerza útil cuando sea al mismo tiempo cuerpo productivo y cuerpo sometido.

5. En el mismo sentido, este par “Trabajo/Descanso” fue el que organizó la vida del sujeto trabajador a partir de una jornada laboral de 8 hs. claramente diferenciada de las jornadas de ocio y distracción (fines de semana/vacaciones). La extensión progresiva del tiempo del salariado, dirá Foucault (1976), supuso una división ceñida del tiempo. Se trata de construir un tiempo íntegramente útil. "La exactitud y la a aplicación son, junto con la regularidad, las virtudes fundamentales del tiempo disciplinario". 


\section{Bibliografía}

BUTLER, J. Cuerpos que importan. Sobre los limites materiales y discursivos del "sexo". Barcelona: Paidós, 2002.

CABRERA, P; ROA, L; LOZANO, C. Fichas del Equipo de Antropología de la Subjetividad: Alquimias Corporales. Buenos Aires: OPFYL, 2011.

CASTELLS, M. La Era de la Información. v. I. La Sociedad Red. México, Distrito Federal: Siglo XXI Editores, 2002.

CITRO, S. Variaciones sobre la corporalidad. In: . Cuerpos Significantes. Travesias de una etnografía dialéctica. Buenos Aires: Biblos, 2009.

. (Coord.). Cuerpos plurales. Antropología de y desde los cuerpos. Buenos Aires: Biblos, 2010.

. La antropología del cuerpo y los cuerpos en-el-mundo. Indicios para una genealogía (in)disciplinar. In: (Coord.). Cuerpos plurales. Antropología de y desde los cuerpos. Buenos Aires: Biblos, 2010.

CSORDAS, T. Modos somáticos de atención. In: CITRO, S. (Coord.). Cuerpos plurales. Antropología de y desde los cuerpos. Buenos Aires: Biblos, 2010.

. Somatic Modes of Attention. Cultural Anthropology, n. 8, p. 135-156, 1993.

. Embodiment as a paradigm for Anthropology. Ethos, v. 18, n. 1, p. 5-47, 1990.

DELEUZE, G. Post-scriptum sobre las sociedades del control. In: Conversaciones 1972-1990. Valencia: Pre-Textos, 1991.

- ¿Qué es un dispositivo? In: BALBIER, E. et al. Michel Foucault, filósofo. Barcelona: Gedisa, 1990.

DELEUZE, G.; PARNET, C. Diálogos. Valencia: Editorial Pre-Textos, 1980.

DESCARTES, R. El discurso del método. Buenos Aires: Alianza, 2011.

FOUCAULT, M. Saber y Verdad. Madrid: La Piqueta, 1984.

- Vigilar y castigar. Nacimiento de la prisión. Madrid: Siglo XXI, 1986.

2006 .

- Seguridad, territorio, población. Buenos Aires: Fondo de Cultura Económica,

FRIGERIO, G.; DIKER, G. (Comps.). Educar: ese acto político. Buenos Aires: Del Estante Editorial, 2005.

GARCÍA FANLO, L. ¿Qué es un dispositivo?: Foucault, Deleuze, Agamben. A Parte Rei Revista de Filosofía, n. 74, 2011.

GRINBERG, S. M. Educación y poder en el siglo XXI. Gubernamentalidad y pedagogía en las sociedades de gerenciamiento. Buenos Aires: Miño y Dávila, 2008. 
GRINBERG, S. M. Tecnologías del gobierno de sí en la era del gerenciamiento: la autoayuda entre el narcisismo y la abyección. Revista Psicoperspectivas: individuo y sociedad, v. 8, n. $2,2009$.

JORNADAS DE SOCIOLOGÍA DE LA UNIVERSIDAD NACIONAL DE LA PLATA. Cambios y continuidades sociales y políticas en Argentina y la región en las últimas décadas, 5., 2008. Buenos Aires. Anais... Buenos Aires: UNLP/FAHCE, 2008.

LE BRETON, D. Sociología del cuerpo. Buenos Aires: Nueva Visión, 2002.

LEWKOWICZ, I. Del fragmento a la situación. Buenos Aires: Altamira, 2003.

ROLDAN, S. El transcurrir del tiempo en la vida escolar en contextos de pobreza: Usos y significaciones en la configuración de nuevas subjetividades. In: MEETING OF THE LATIN AMERICAN STUDIES ASSOCIATION. 2009, Rio de Janeiro. Anais... Rio de Janeiro, 2009.

SCAVINO, D. Nomadología. Una lectura de Deleuze. Buenos Aires: Ediciones del Fresno, 1991.

VARELA, J.; ÁLVAREZ-URIA, F. Arqueología de la Escuela. España: La Piqueta, 1991.

Recebido em 09 de setembro de 2014.

Aprovado em 31 de julho de 2015.

DOI: $\underline{\text { http://dx.doi.org/10.1590/ES0101-73302015140391 }}$ 